\title{
Analisis Mekanisme Failover Controller Pada Software Defined
} Network

\author{
Jurdan Wahyu Adi S*1, Mahar Faiqurahman², Fauzi Dwi Setiawan Sumadi ${ }^{3}$ \\ 1,2,3 Universitas Muhammadiyah Malang \\ jurdan.aho@gmail.com”, mahar@umm.ac.id², fauzisumadi@umm.ac.id ${ }^{3}$
}

\begin{abstract}
Abstrak
Software Defined Network ( $S D N$ ) merupakan konsep teknologi jaringan untuk mendesain, mengelola, dan mengimplementasikan suatu jaringan dengan melakukan pemisahan antara control plane dan forwarding plane yang kemudian dikendalikan melalui satu media aplikasi controller yang melewati satu protocol. Controller SDN bertugas untuk mengatur aliran data antara data plane dan control plane. Pada konsep SDN memungkinkan adanya kegagalan komunikasi antar jaringan yang bisa saja terjadi. Kegagalan yang bisa saja terjadi, misalnya salah satu controller dalam jaringan SDN mengalami down ataupun tidak aktif sehingga host tidak dapat terhubung dengan baik. Untuk mengatasi permasalahan tersebut perlu adanya sistem yang menanganinya seperti High Availability Controller. High Availability Controller dapat dilakukan dengan mekanisme failover menggunakan Heartbeat dan DRBD (Distributed Replication Block Device). Tujuan dari penerapan aplikasi tersebut untuk melakukan failover ketika terjadi kegagalan ataupun down pada controller utama maka peran controller utama akan di pindahkan ke controller backup supaya controller tetap tersedia meskipun terjadi down dan DRBD melakukan sinkronisasi data pada partisi disk yang telah dibuat secara realtime, membentuk replication disk. Replication disk akan diakses secara bergantian oleh server menggunakan Heartbeat. Pengujian dalam penelitian ini yaitu dengan mengukur rata rata waktu failover Ketika server backup mengambil alih peran server utama. Berdasarkan hasil pengujian failover dari controller RYU, POX , dan OpenDayLight menunjukan hasil bahwa controller RYU memiliki rata rata waktu yang lebih singkat yaitu $1.3 \mathrm{sec}$ dibandingkan dengan controller POX yang memiliki rata rata waktu lebih lama yaitu $23.3 \mathrm{sec}$ dan ODL yang meimiliki rata rata waktu $1.5 \mathrm{sec}$. Perbedaan hasil tersebut bergantug jenis controller yang digunankan, dimana semakin banyak fitur yang dijalankan sebuah controller maka semakin lama waktu failover yang di hasilkan. Hal tersebut terjadi karena dibutuhkan waktu tambahan untuk menjalankan fitur fitur controller yang digunakan.
\end{abstract}

Kata Kunci: HA, Failover,QOS,SDN.

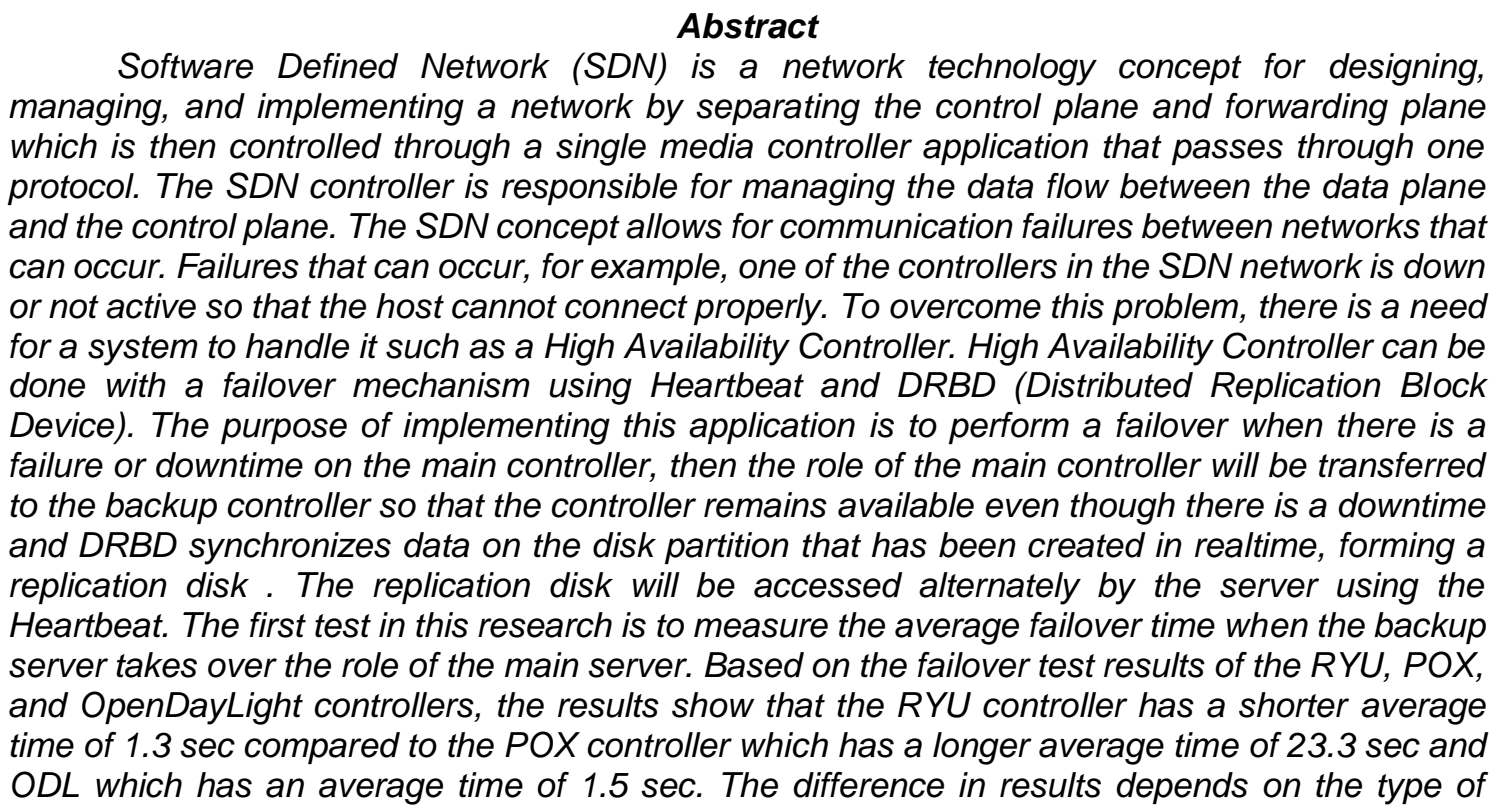


controller used, where the more features a controller executes, the longer the failover time it produces. This happens because it takes additional time to run the controller features used.

\section{Keywords: HA, Failover, QOS,SDN}

\section{Pendahuluan}

Software Defined Network (SDN) merupakan konsep teknologi jaringan untuk mendesain, mengelola, dan mengimplementasikan suatu jaringan dengan melakukan pemisahan antara control plane dan forwarding plane yang kemudian dikendalikan melalui satu media aplikasi controller yang melewati satu protocol [1]. Tujuan dari SDN adalah untuk meningkatkan ketersediaan jaringan, manajemen jaringan, mengurangi biaya jaringan, dan mengembangkan inovasi jaringan [2]. Controller SDN bertugas untuk mengatur aliran data antara data plane dan control plane. Terdapat beberapa jenis controller antara lain Beacon, Onix, ONOS, OpenDayLight, Open Contrail, Ryu, POX dan Floodlight [3]. Sedangkan protokol yang digunakan untuk komunikasi antara perangkat dan media aplikasi controller adalah protocol OpenFlow. OpenFlow diperumpamakan seperti jembatan yang mengendalikan perangkat berdasarkan MAC, IP Address atau TCP Port untuk melakukan perintah tertentu [1].

Pada konsep SDN memungkinkan adanya kegagalan komunikasi antar jaringan yang bisa saja terjadi. Kegagalan yang bisa saja terjadi, misalnya salah satu controller dalam jaringan SDN mengalami down ataupun tidak aktif sehingga host tidak dapat terhubung dengan baik. Untuk mengatasi permasalahan tersebut perlu adanya sistem yang menanganinya seperti High Availability.

High Availability merupakan kemampuan suatu sistem dalam menjaga layanan atau aplikasi yang sedang berjalan dan dapat memulihkan dari kegagalan komponen atau sistem dengan dampak penghentian aplikasi yang minimum [1]. Pada konsep High Availability terdapat 2 jenis salah satunya failover availability. Failover availability menggunakan dua buah server yaitu server utama dan server backup dengan data yang identik pada masing-masing server [1]. Ketika sistem dengan konsep ini berjalan normal, hanya server utama yang bertugas untuk melayani seluruh user, sedangkan ketika server utama mengalami down dan server backup mendeteksi hal tersebut, maka server backup akan menggantikan fungsi dari server utama [1]. Sehingga mekanisme failover merupakan teknik jaringan dengan memberikan dua jalur koneksi atau lebih ketika salah satu jalur down dengan mengalihkan ke jalur lainnya [1]

Berdasarkan pada literatur penelitian sebelumnya dan permasalahan yang telah disampaikan, penulis melakukan penelitian dengan judul "Analis Mekanisme Failover Controller pada Software Defined Network". Penelitian yang akan dilakukan yaitu dengan membandingkan controller RYU dengan POX, dan ODL. Parameter yang akan diuji pada penelitian ini ada 2, pertama adalah pengukuran pada waktu rata-rata failover controller dimana controller utama tidak aktif sehingga tugas diambil alih oleh controller backup. Kedua adalah pengukuran pada parameter QoS seperti jitter, packet loss, dan throughtput dengan menganalisis selama proses failover terjadi.

Untuk mendukung penelitian ini maka diperlukan aplikasi Heartbeat dan Distributed Replicated Block Device (DRBD) untuk mendukung sistem High Availability Controller (HAC). Tujuan dari penerapan aplikasi tersebut untuk melakukan failover ketika terjadi kegagalan ataupun down pada controller utama maka peran controller utama akan di pindahkan ke controller backup supaya controller tetap tersedia meskipun terjadi down dan DRBD melakukan sinkronisasi data pada partisi disk yang telah dibuat secara realtime, membentuk replication disk. Replication disk akan diakses secara bergantian oleh server menggunakan Heartbeat.

\section{Metode Penelitian \\ 2.1 Perancangan Sistem}

Dalam implementasi penelitian tugas akhir, akan dibuat sebuah rancangan sistem yang merupakan awal prores implementasi, agar penelitian ini sesuai dengan batasan masalah dan tujuan masalah. Beberapa komponen yang diperlukan yaitu controller, emulator mininet. Bahasa pemrograman yang digunakan yaitu java dan python, parameter yang akan diuji adalah Failover, Packet loss, Jitter dan Troughput pada controller SDN menggunakan wireshark dan iperf. Topologi jaringan yang digunakan akan dijalankan pada emulator mininet dan menggunakan controller RYU, ODL, dan POX. Berikut rancangan untuk implementasi failover controller pada SDN. 


\subsubsection{Topologi Jaringan}

Dari rumusan diatas, dalam tahap ini akan menerapkan heartbeat untuk melakukan failover apabila controller utama down maka heartbeat akan secara otomatis mengarahkan peran controller utama kepada controller backup dan DRBD melakukan backup keseluruhan dari controller utama ke controller backup secara realtime pada Software Defined Network dengan menggunakan bahasa pemograman Python. Topologi yang digunakan seperti Gambar 1.

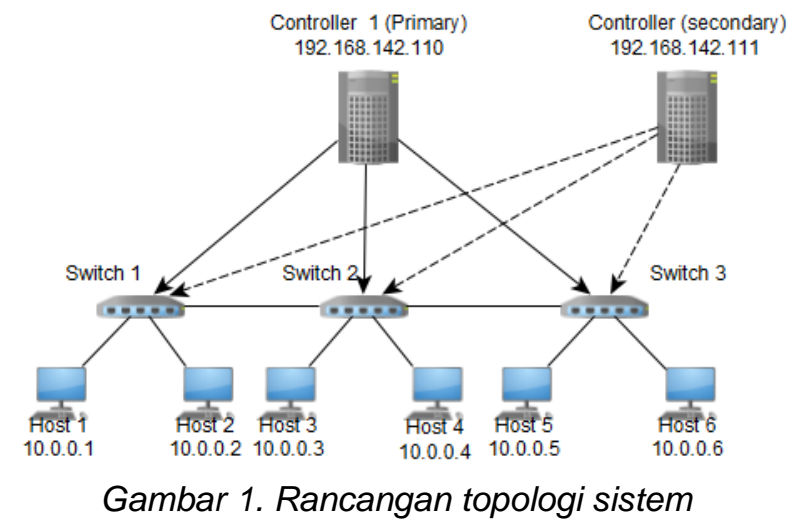

Infrastruktur jaringan SDN yang di implementasikan pada mininet menggunakan topologi sederhana dimana terdapat 2 controller yaitu controller utama dan controller backup, 3 switch, 6 host, komponen tersebut memiliki fungsi masing-masing sebagai berikut :

1. Controller bertugas mengontrol jaringan dan meneruskan paket ke switch. Controller akan dijalankan oleh RYU, POX, dan OpenDayLight yang bertindak sebagai wewenang terhadap controller.

2. Switch berfungsi untuk mengirimkan data dari host pengirim ke host tujuan dengan Flowrule yang telah ditetapkan oleh controller. Pada switch menggunakan Open Virtual Switch (OVS) untuk memisahkan control plane dan data plane agar dapat dilakukan pengontrolan secara terpusat .

3. Host berfungsi untuk menguji performansi jaringan dengan melakukan pengiriman data.

4. OpenFlow berfungsi untuk menghubungkan antara control layer dan forwarding layer.

\subsubsection{Pembangunan Sistem}

Setelah merancang topologi seperti Gambar 1, maka selanjutnya pembangunan sistem agar mengetahui bagaimana sistem bekerja sesuai penelitian, rancangan sistem yang di gunakan seperti Gambar 2.

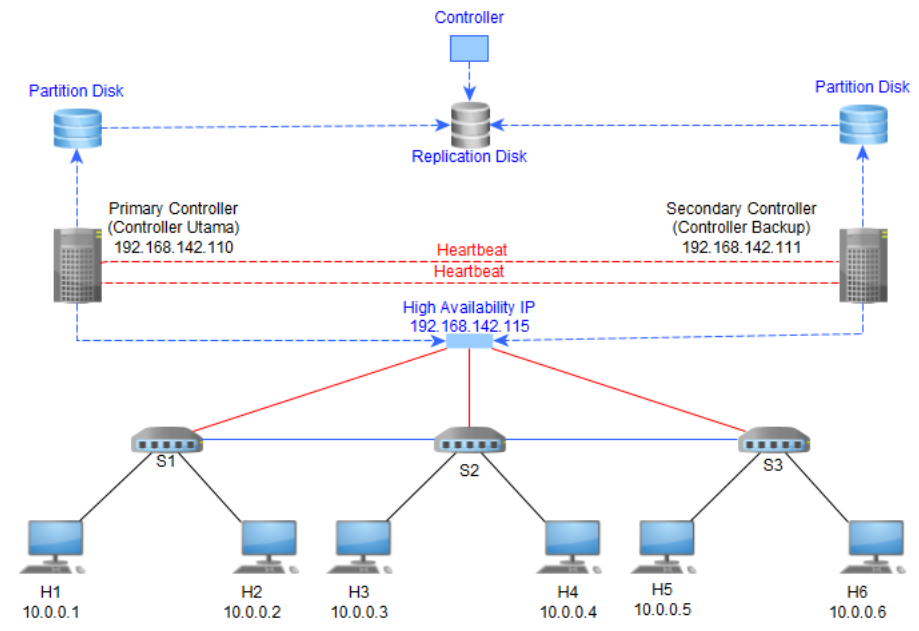

Gambar 2. Mekanisme Failover Controller 
Penelitian ini berfokus pada implementasi failover menggunakan Heartbeat dan DRBD pada jaringan SDN. Pada Gambar 2 akan dibuat 3 buah VM (Virtual Machine), yakni VM untuk controller utama (primary server), VM untuk controller backup (secondery server), dan VM untuk Mininet. Heartbeat pada Controller utama dan controller backup melakukan komunikasi data menggunakan IP Address yang telah dikonfigurasi pada kedua controller IP 192.168.14.110 pada primary controller dan IP 192.168.142.111 pada secondary controller. Controller utama dan controller backup, disediakan partisi yang identik atau sama. DRBD melakukan sinkronisasi data pada partisi disk yang telah dibuat secara realtime dan membentuk replication disk. Controller ditempatkan pada Replication disk yang akan diakses secara bergantian oleh server menggunakan Heartbeat, dimana jika controller utama down maka Replication disk akan akses oleh server backup. Mininet sebagai infrastruktur jaringan, akan mengarah ke IP 192.168.142.115 yang telah dibuat oleh Heartbeat. IP heartbeat tersebut akan digunakan secara bergantian pada kedua controller, Ketika controller utama masih menyala maka IP Heartbeat akan digunakan pada controller utama, apabila controller utama mati atau down maka IP heartbeat tersebut akan digunakan pada controller backup. Sehingga terbentuk suatu High Availability IP yang nantinya akan menjadi akses remote controller pada Mininet untuk terhubung dengan controller.

\subsubsection{Kebutuhan Software}

1. Ubuntu Desktop

Ubuntu merupakan salah satu produk yang didistribusikan oleh Linux dengan berbasis Debian dan didistribusikan secara gratis.

2. VirtualBox

VirtualBox merupakan perangkat lunak virtualisasi yang dapat digunakan untuk mengeksekusi sistem operasi tambahan di dalam sistem operasi utama.

3. Controller RYU

Ryu merupakan sebuah kontroler dari SDN yang bersifat open source dan menggunakan bahasa pemrograman phyton untuk memenejemen dan mengontrol jaringan serta meningkatkan kelincahan jaringan dengan mudah mengatur dan menyesuaikan bagaimana lalu lintas ditangani [7]. RYU memiliki Application Program Interface (API) yang terdefinisi dengan baik untuk pengembangan aplikasi jaringan yang telah digunakan secara luas oleh para peneliti [7].

4. Controller POX

Controller POX merupakan sebuah controller berbasis bahasa pemrograman Python yang digunakan untuk mengembangkan perangkat lunak SDN Controller [10]. POX juga dapat digunakan untuk membangun SDN controller yang diimplementasikan pada jaringan fisik maupun virtual [10]

5. Controller OpenDayLight

OpenDayLight adalah controller yang bersifat open source di bawah naungan Linux Foundation menggunakan bahasa pemrograman Java [11]. Tujuannya adalah untuk mengimplementasikan dan berinovasi pada SDN [14].

6. Python

Python adalah bahasa pemrograman yang digunakan untuk membuat aplikasi yang akan dijalankan controller POX dan RYU.

7. Java

Java adalah bahasa pemrograman yang digunakan untuk membuat aplikasi yang akan dijalankan controller ODL.

8. Mininet

Mininet merupakan sebuah emulator jaringan yang dapat digunakan untuk mensimulasikan jaringan seperti switch, host, dan controller SDN dalam satu perintah[6]. Mininet juga dapat digunakan untuk mengemulasi data plane atau infrastructure layer dalam perancangan jaringan SDN [6].

9. Hearbeat

Heartbeat merupakan aplikasi yang digunakan untuk melakukan failover apabila server utama down maka hearbeat akan secara otomatis mengarahkan peran server utama kepada server backup[1].

10.DRBD (Distributed Replicated Block Device)

DRBD adalah storage block device yang dirancang untuk membangun High Availability sistem dan yang melakukan suatu sinkronisasi 2 server dengan metode Uptime, Synchronous

REPOSITOR, Vol. 3, No. 5, November 2021: 513-522 
dan Asynchronous [12]. Kinerja DRBD dilakukan dengan cara mirroring terhadap semua melalui jaringan serta menggunakan jaringan sebagai media transmisi untuk melakukan sinkronisasi data antar disk secara realtime.

11. Wireshark

Wireshark merupakan sebuah aplikasi untuk menganalisa sebuah jaringan dengan memeriksa koneksi antara host dan server, lalu menangkap aliran aktivitas pada sebuah jaringan [15].

12.Iperf

Iperf merupakan tool untuk mengukur troughput bandwidth dalam sebuah jalur network, agar bisa dilakukan pengukuran diperlukan iperf yang terinstall point to point, baik disisi server maupun client [15].

\subsubsection{Kebutuhan Hardware}

Laptop yang di gunakan adalah Acer Aspire E 14 dengan spesifikasi prosesor Intel ${ }^{\circledR}$ Core $^{\mathrm{TM}}$ i5-7200U CPU @ 2.50 Ghz, RAM 8 GB (dual channel 4 GB + 4 GB), menggunakan 2 penyimpanan yaitu SSD $120 \mathrm{~GB}$ dan SSHD 500GB

\section{Hasil Penelitian dan Pembahasan}

Pada tahap ini peniliti akan menjelaskan hasil dari pengujian dan analisa sistem yang telah dirancang. Pengujian dilakukan dengan maksud untuk menilai kinerja dari perancangan sistem apakah telah memenuhi kriteria yang diinginkan dengan melakukan analisis kinerja sistem failover.

Pada pengujian ini akan dilakukan dengan cara melakukan beberapa tes failover pada sistem ini, sehingga sistem ini kembali menjadi keadaan semula dimana server utama menjadi pusat Controller Software Defined Network yang sedang berjalan. Pengujian yang akan dilakukan meliputi kemampuan failover pada kedua server, serta waktu yang dibutuhkan untuk melakukan proses tersebut

\subsection{Pengujian Failover}

Pengujian failover merupakan pengujian yang dilakukan ketika server utama mengalami kegagalan atau mati, maka server kedua akan mengambil alih fungsi dari server utama. Pengujian failover yang akan dilakukan digunakan untuk membandingkan rata rata waktu failover mana yang paling cepat dari controller RYU, POX, dan ODL.

Untuk melakukan pengujian failover dapat dilakukan dengan mematikan server utama secara langsung, dengan kondisi seperti ini maka semua resources dari server utama akan segera dipindahkan ke server kedua dan menjalankan service pada server kedua untuk melakukan tugasnya seperti server utama. Berikut adalah hasil pengujian failover.

Tabel 1. Hasil keseluruhan pengujian failover controller RYU, POX, dan ODL

\begin{tabular}{cccc}
\hline \multirow{2}{*}{ Pengujian 1 } & \multicolumn{3}{c}{ Waktu yang dibutuhkan (s) } \\
\cline { 2 - 4 } & Ryu & POX & ODL \\
\hline 1 & 1 & 24 & 2 \\
2 & 2 & 33 & 1 \\
3 & 1 & 14 & 2 \\
4 & 1 & 28 & 1 \\
5 & 1 & 10 & 2 \\
6 & 2 & 29 & 1 \\
7 & 1 & 27 & 2 \\
8 & 1 & 26 & 1 \\
9 & 2 & 28 & 1 \\
10 & 1 & 14 & 2 \\
\hline Total & 13 & 233 & 15 \\
\hline Rata - Rata & 1.3 & 23.3 & 1.5 \\
\hline
\end{tabular}

Setelah dilakukan pengujian didapatkan hasil seperti yang ditunjukan pada Tabel 1 , selanjutnya dari hasil pengujian tersebut akan disajikan dalam bentuk grafik perbandingan pada Gambar 3. 


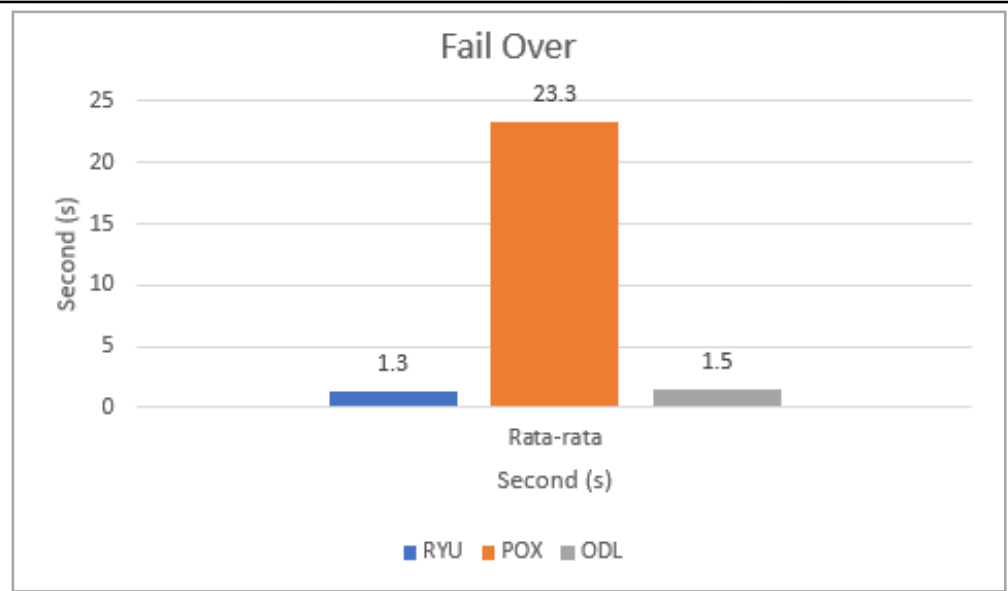

Gambar 3. Grafik perbandingan failover controller Ryu, Pox, dan ODL

Berdasarkan hasil pengujian failover dari ketiga controller tersebut setelah melakukan 10 kali percobaan menunjukan hasil bahwa controller RYU memiliki rata rata waktu yang lebih singkat yaitu $1.3 \mathrm{sec}$ dibandingkan dengan controller POX yang memiliki rata rata waktu lebih lama yaitu $23.3 \mathrm{sec}$ dan ODL yang meimiliki rata rata waktu $1.5 \mathrm{sec}$. Hasil tersebut bergantug pada jenis controller yang digunankan, dimana pada masing masing controller memiliki perbedaan fitur yang dijalankan. Pada controller POX memiliki fitur yang lebih kompleks dibandingankan dengan controller lain, sehingga dapat berpengaruh pada waktu yang dibutuhkan oleh controller POX untuk melakukan failover.

\subsection{Pengujian dan Analisa Throughput}

Pengujian Quality of Service yaitu throughput dilakukan dengan maksud untuk mengetahui kemampuan suatu jaringan dalam hal pengiriman data secara aktual. Throughput merupakan jumlah total kedatangan data yang sukses diamati pada node tujuan selama interval tertentu dan dibagi dengan durasi interval waktu tersebut. Pengujian yang akan dilakukan yaitu menggunakan aplikasi iperf dengan melakukan pegiriman paket dari h3 yang akan menjadi client sedangkan h1 akan menjadi server yang akan mengirimkan trafic UDP selama 200 detik.

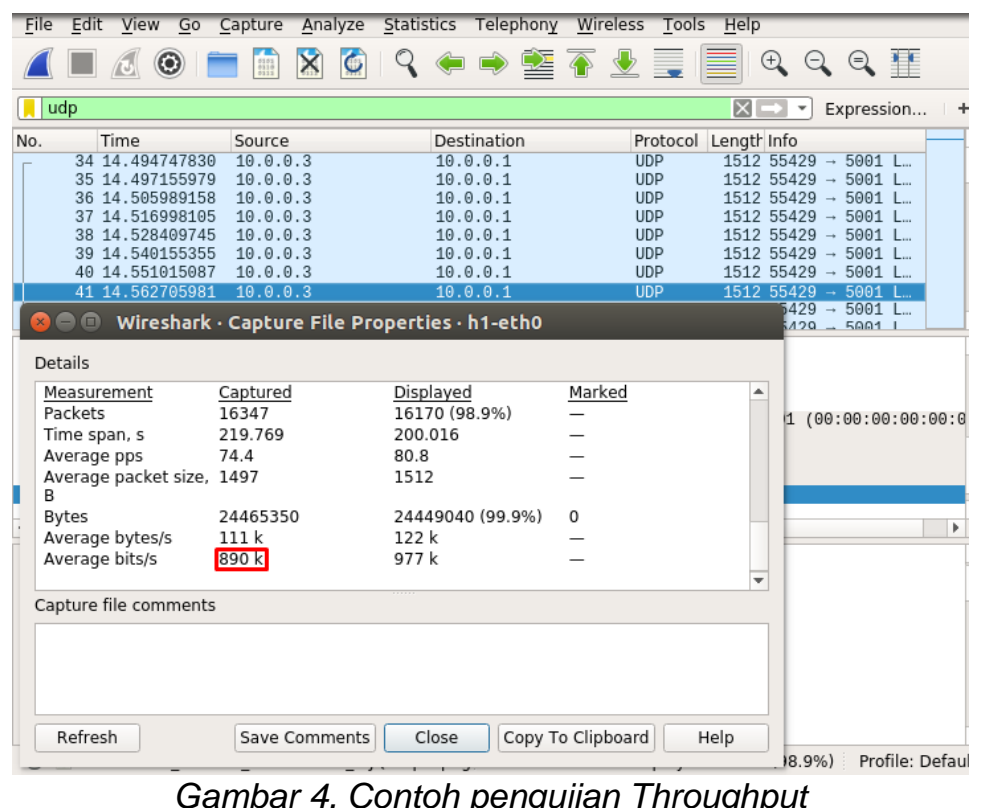

Pengecekan nilai throughput menggunakan aplikasi wireshark yang telah melakukan monitoring traffic jaringan bersamaan dengan pengujian jitter dan packet loss yang dijalankan pada aplikasi iperf. Pada Gambar 4 merupakan contoh pengambilan nilai throughput.

REPOSITOR, Vol. 3, No. 5, November 2021: 513-522 
Tabel 2. Hasil pengujian throughput

\begin{tabular}{cccc}
\hline \multirow{2}{*}{ Pengujian 2 } & \multicolumn{3}{c}{ Throughput (kbps) } \\
\cline { 2 - 4 } & Ryu & POX & ODL \\
\hline 1 & 943 & 491 & 328 \\
2 & 549 & 890 & 549 \\
3 & 1051 & 855 & 335 \\
4 & 1052 & 571 & 868 \\
5 & 1052 & 760 & 929 \\
6 & 1051 & 115 & 931 \\
7 & 1051 & 194 & 442 \\
8 & 544 & 769 & 404 \\
9 & 985 & 907 & 1017 \\
10 & 1051 & 636 & 414 \\
\hline Total & 9329 & 6188 & 6217 \\
\hline Rata - Rata & 932.9 & 618.8 & 621.7 \\
\hline
\end{tabular}

Setelah dilakukan pengujian didapatkan hasil seperti yang ditunjukan pada Tabel 2 , selanjutnya dari hasil pengujian tersebut akan disajikan dalam bentuk grafik perbandingan pada Gambar 5.

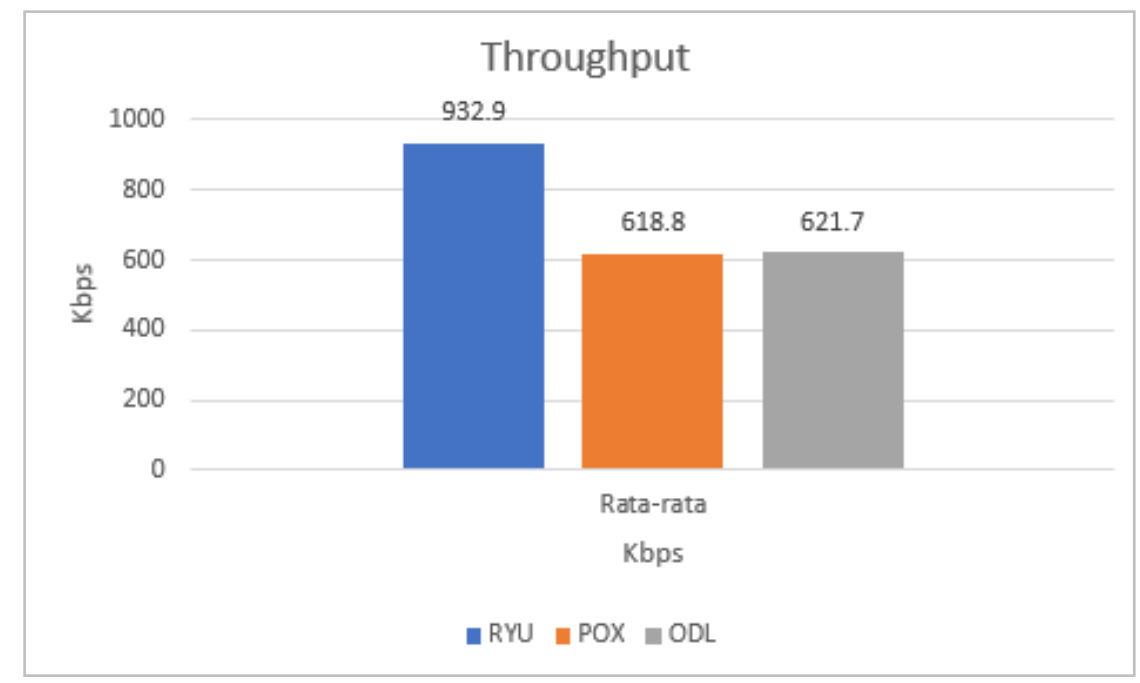

Gambar 5. Grafik perbandingan troughput controller RYU, POX, dan ODL

Berdasarkan hasil pengujian throughput dari ketiga controller tersebut setelah melakukan 10 kali percobaan menunjukan hasil bahwa controller RYU memiliki rata rata troughput yang lebih tinggi yaitu 932.9 kbps dibandingkan dengan controller POX yang memiliki rata rata throughput lebih rendah yaitu $618.8 \mathrm{kbps}$ dan ODL yang meimiliki rata rata throughput $621.7 \mathrm{kbps}$. Hal ini dikarenakan semakin lama waktu yang dibutuhkan untuk proses failover controller, maka akan mempengaruhi jumlah kecepatan data yang akan dikirim ke semua terminal dalam jaringan. Pada Gambar 3.3 dapat dilihat bahwa controller POX memiliki waktu proses failover yang lebih tinggi daripada yang lain, sehingga berakibat nilai throughput yang dihasilkan lebih rendah daripada yang lain.

\subsection{Pengujian dan Analisa Jitter}

Pengujian jitter dilakukan untuk mengetahui variasi delay antara pengiriman data pada jaringan yang dapat terjadi karena dipengaruhi beban traffic pada jaringan itu sendiri. Pengujian jitter dilakukan bersamaan dengan pengujian packet loss. Pada Gambar 6 akan ditunjukan contoh pengujian jitter dan packet loss. 


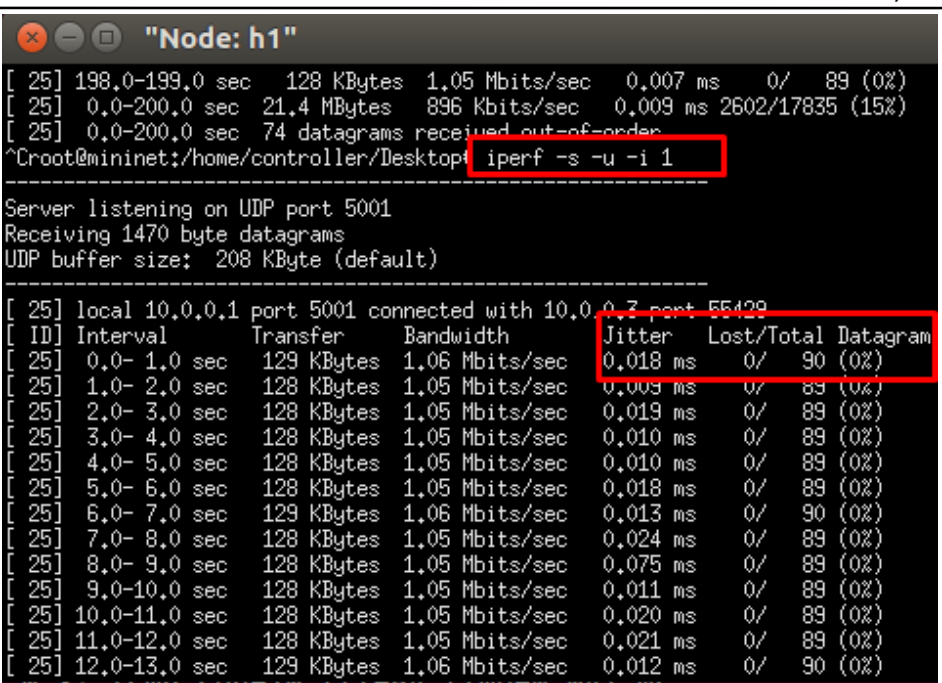

Gambar 6. Pengujian Jitter dan Packet Loss

Pengujian jitter dilakukan secara bersamaan dengan pengujian packet loss menggunakan aplikasi iperf, dimana h1 sebagai server dan h3 sebagai client mengirimkan traffic UDP selama 200 detik.

Tabel 3. Hasil pengujian jitter

\begin{tabular}{cccc}
\hline \multirow{2}{*}{ Pengujian 3 } & \multicolumn{3}{c}{ Jitter $(\mathrm{ms})$} \\
\cline { 2 - 4 } & Ryu & POX & ODL \\
\hline 1 & 0.139 & 0.009 & 0.081 \\
2 & 0.009 & 0.008 & 0.15 \\
3 & 0.006 & 0.016 & 0.054 \\
4 & 0.017 & 0.009 & 0.374 \\
5 & 0.005 & 0.007 & 0.049 \\
6 & 0.011 & 0.011 & 0.153 \\
7 & 0.008 & 0.007 & 0.058 \\
8 & 0.011 & 0.005 & 0.68 \\
9 & 0.01 & 0.008 & 0.023 \\
10 & 0.008 & 0.012 & 0.098 \\
\hline Total & 0.224 & 0.092 & 1.72 \\
\hline Rata-Rata & 0.0224 & 0.0092 & 0.172 \\
\hline
\end{tabular}

Setelah dilakukan pengujian didapatkan hasil seperti yang ditunjukkan pada Tabel 3 , selanjutnya dari hasil pengujian tersebut akan disajikan dalam bentuk grafik perbandingan pada Gambar 7.

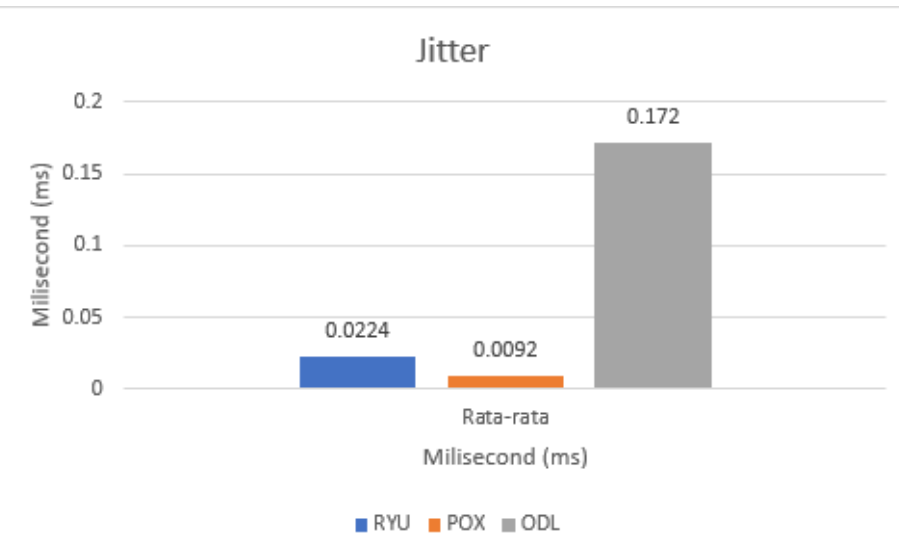

Gambar 7. Grafik Perbandingan Jitter controller RYU, POX, dan ODL

REPOSITOR, Vol. 3, No. 5, November 2021: 513-522 
Berdasarkan hasil pengujian jitter dari ketiga controller tersebut setelah melakukan 10 kali percobaan menunjukan hasil bahwa controller POX memiliki rata rata jitter yang lebih baik yaitu 0.0092 ms dibandingkan dengan controller ODL yang memiliki rata rata jitter lebih tinggi yaitu $0.172 \mathrm{~ms}$ dan controller RYU yang meimiliki rata rata jitter $0.0224 \mathrm{~ms}$. Hasil dari pengujian jitter dari ketiga controller tersebut masih tergolong bagus. Faktor yang mempengaruhi nilai jitter diantaranya variasi dalam panjang antrian pengiriman data, waktu pengelolaan data, dan juga dalam waktu penghimpunan ulang packet-packet diakhir perjalanan.

\subsection{Pengujian dan Analisa Packet Loss}

Pengujian packet loss dilakukan untuk mengetahui jumlah data yang dikirim tidak diterima oleh node tujuan dikarena beberapa faktor antara lain terjadinya overload traffic jaringan, terjadinya congestion atau tabrakan, ataupun kegagalan pada sisi penerima. Pengujian packet loss dilakukan bersamaan dengan pengujian jitter menggunakan iperf.

Tabel 4. Hasil pengujian Packet Loss

\begin{tabular}{cccc}
\hline \multirow{2}{*}{ Pengujian 3 } & \multicolumn{3}{c}{ Packet Loss (\%) } \\
\cline { 2 - 4 } & Ryu & POX & ODL \\
\hline 1 & 0.27 & 16.4 & 0.32 \\
2 & 0.31 & 9.3 & 0.33 \\
3 & 0.3 & 6.7 & 0.31 \\
4 & 0.24 & 8.7 & 0.34 \\
5 & 0.32 & 4.6 & 0.3 \\
6 & 0.37 & 14 & 0.31 \\
7 & 0.31 & 13 & 0.32 \\
8 & 0.26 & 15 & 0.31 \\
9 & 0.34 & 14 & 0.31 \\
10 & 0.3 & 9.7 & 0.42 \\
\hline Total & 3.02 & 111.4 & 3.27 \\
\hline Rata - Rata & 0.302 & 11.14 & 0.327 \\
\hline
\end{tabular}

Setelah dilakukan pengujian didapatkan hasil seperti yang ditunjukkan pada Tabel 4, selanjutnya dari hasil pengujian tersebut akan disajikan dalam bentuk grafik perbandingan pada Gambar 8.

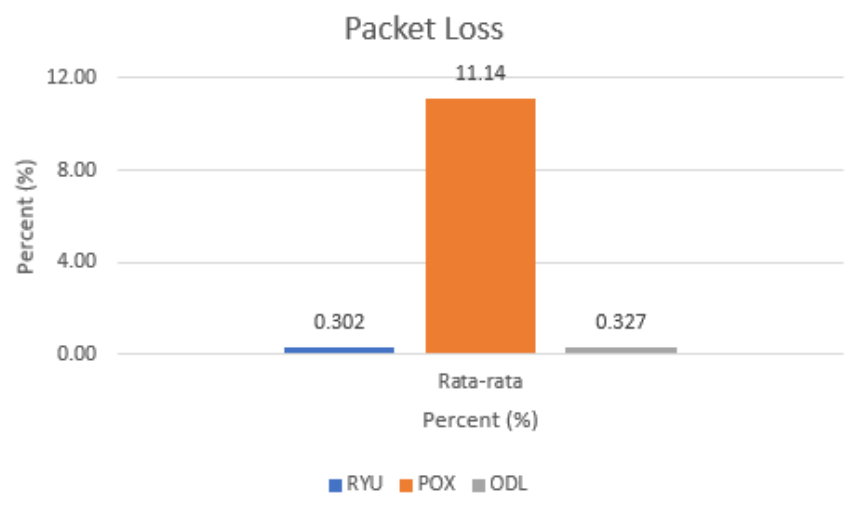

Gambar 8. Grafik Perbandingan Packet Loss controller RYU, POX, dan ODL

Berdasarkan hasil pengujian packet loss dari ketiga controller tersebut setelah melakukan 10 kali percobaan menunjukan hasil bahwa controller RYU memiliki rata rata packet loss yang lebih sedikit yaitu $0.302 \%$ dibandingkan dengan controller POX yang memiliki rata rata lebih tinggi yaitu $11.14 \%$ dan controller ODL yang meimiliki rata rata packet loss $0.327 \%$. Kenaikan packet loss dipengaruhi oleh lama waktu yang dibutuhkan pada saat proses failover. Semakin lama waktu yang dibutuhkan pada saat failover maka nilai packet loss akan semakin besar. Pada Gambar 3.3 dapat dilihat bahwa controller POX memiliki waktu proses failover yang lebih tinggi daripada yang lain, sehingga berakibat nilai packet loss yang dihasilkan lebih tinggi daripada yang lain. 


\section{Kesimpulan}

Berdasarkan implementasi dan pengujian yang telah dilakukan dapat ditarik kesimpulan bahwa Mekanisme failover controller menggunakan Heartbeat dan DRBD dilakukan dengan membagi peran controller menjadi controller utama dan controller backup. Apabila controller utama mati atau down, maka controller backup akan mengambil alih tugas controller utama.

Rata rata kecepatan waktu dalam proses failover relatif singkat dengan urutan Controller RYU diikuti dengan controller ODL dan controller POX. Hasil tersebut bergantug pada jenis controller yang digunankan, dimana pada masing masing controller memiliki perbedaan fitur yang dijalankan. Pada controller RYU memiliki fitur yang lebih komplek dibandingankan dengan controller lain.

Hasil perbandingan Pengujian parameter QOS pada controller RYU, POX, dan ODL menunjukan bahwa controller RYU mempunyai nilai yang lebih baik dibandingkan dengan controller POX dan ODL. Pengujian throughput pada controller RYU memiliki rata rata yang lebih tinggi dibandingkan controller POX dan ODL. Sedangkan pada pengujian jitter controller ODL memiliki rata rata nilai jitter yang lebih tinggi diikuti dengan controller RYU dan POX. Dan pada pengujian packet loss controller RYU memiliki rata rata nilai yang lebih rendah dibanding dengan controller ODL dan POX. Sehingga dapat disimpulkan bahwa lama waktu yang dibutuhkan pada saat proses failover berpengaruh pada hasil pengujian parameter QOS.

\section{Referensi}

[1] M. Purwiadi, W. Yahya, and A. Basuki, "High Availability Controller Software Defined Network Menggunakan Heartbeat dan DRBD," vol. 2, no. 8, pp. 2297-2306, 2018.

[2] A. Rizki, D. Nugraha, R. M. Negara, and D. D. Sanjoyo, "High Availability Performance on OpenDayLight SDN Controller Platform ( OSCP) Clustering and OpenDayLight with Heartbeat-Distributed Replicated Block Device ( DRBD )," vol. 10, no. 3, pp. 149-156, 2018.

[3] R. S. V. Pashkov, A. Shalimov, "Controller Failover For SDN Enterprise Networks," vol. 1, 2014.

[4] D. A. Gita, S. R. Akbar, and W. Yahya, "Implementasi Server Failover Pada Software Defined Network," vol. 3, no. 1, pp. 133-139, 2019.

[5] M. H. Hidayat, N. R. Rosyid, Y. Sekip, U. Iv, and Y. Indonesia, "Analisis Kinerja dan Karakteristik Arsitektur Software-Defined Network Berbasis OpenDaylight Controller," pp. 194-200, 2017.

[6] E. P. Aprilianingsih, R. Primananda, and A. Suharsono, "Analisis Fail Path Pada Arsitektur Software Defined Network Menggunakan Dijkstra Algorithm,” vol. 1, no. 3, pp. 174-183, 2017.

[7] Y. S. H. Roni Fernando Simarmata1, Rohmat Tulloh2, "Simulasi Jaringan Software Defined Network Menggunakan Protokol Routing Ospf Dan Ryu Controller,” vol. 4, no. 3, pp. 28872896, 2018.

[8] R. Khondoker, K. Bayarou, and F. Weber, "Security Analysis of OpenDaylight , ONOS , Rosemary and Ryu SDN Controllers," pp. 37-44, 2016.

[9] M. Nuruzzamanirridha, I. Dyah, and Y. S. Hariyani, "Implementasi Jaringan Komputer Berbasis Software Defined Network Menggunakan RYU Controller Dan Openvswitch Implementation Of Computer Network Based-On Software Defined Network Using RYU Controller and Openvswitch," vol. 2, no. 2, 2016.

[10] D. Prayoga, R. M. ljtihadie, and M. Husni, "Implementasi POX pada Perangkat Lunak Software-Defined Networking Controller untuk Data Center Berbasis Container," vol. 6, no. 2, pp. 352-355, 2017.

[11] R. Purnomo, T. Informatika, U. Bhayangkara, and J. Raya, "Analisis QOS Dengan Virtual Tenant Network Pada," vol. 5, no. 2, 2019.

[12] T. S. Mohammad Faruq Afif, "Implementasi Disaster Recovery Plan Dengan Sistem Fail Over Menggunakan Drbd Dan Heartbeat Pada Data Center Fkip Uns," vol. 2, pp. 64-69, 2013.

[13] I. Iskandar and A. Hidayat, "Analisa Quality of Service ( QoS ) Jaringan Internet Kampus ( Studi Kasus : UIN Suska Riau )," vol. 1, no. 2, pp. 67-76, 2015.

[14] I. Technology, "Performance Evaluation of SDN Controllers : Floodlight And," vol. 17, no. 2, pp. 47-57, 2016.

[15] M. Karakus and A. Durresi, "Quality of Service ( QoS ) in Software Defined (SDN): A Survey," J. Netw. Comput. Appl., 2016.

REPOSITOR, Vol. 3, No. 5, November 2021: 513-522 